\title{
Business models and cost analysis of automated valet parking and shared autonomous vehicles assisted by internet of things
}

Proc IMechE Part D:

$\int$ Automobile Engineering

I-I4

(c) IMechE 202I

(c) (i) \&)

Article reuse guidelines:

sagepub.com/journals-permissions DOI: 10.1 I 77/0954407021994445 journals.sagepub.com/home/pid @SAGE

\author{
Junyan Chen', Haibo Chen', Jianbing Gao' $(D$, , Kaushali Dave' and Romina \\ Quaranta ${ }^{2}$
}

\begin{abstract}
With the rapid development of autonomous vehicles, it is necessary to explore new business opportunities, especially under the assistance of internet of things, which accelerate the penetration in vehicle markets. Automated valet parking and shared autonomous vehicles will be the most active cases promoted by autonomous driving. In this paper, the business models of automated valet parking and shared autonomous vehicles were proposed, further, the cost structures of autonomous vehicles under two cases were investigated from points of car users and owners. In the business models, autonomous driving packages, internet of things devices, and service provider companies are considered as new stakeholders. The cost structure of automated valet parking users changes greatly, with the development of autonomous driving packages whose cost share decreases from $\sim 60 \%$ to $\sim 5 \%$. The total cost of automated valet parking users is much higher than conventional parking before 2024. Additionally, the use of shared vehicles relieves financial burden, without trouble of periodical maintenance. For station-based and free-floating car sharing, the price drop of autonomous driving package brings about huge benefits for companies. Peer-to-peer car sharing business effectively decreases financial burden of car owners such that the decrease is less than $20 \%$ starting from 2017.
\end{abstract}

\section{Keywords \\ Autonomous vehicle, internet of things, business models, cost structure, automated valet parking, shared autonomous vehicles}

Date received: 25 November 2020; accepted: 18 January 2021

\section{Introduction}

The development of autonomous vehicles (AVs) are primarily driven by the need for an optimal transport system and high quality of life. ${ }^{1,2}$ According to the previous studies, ${ }^{3,4}$ the adoption of AVs can contribute to decrease in energy and fuel consumption, pollution and traffic congestion, whilst increasing safety and transport accessibility, to some extent. As indicated by Igliński and Babiak, ${ }^{5}$ AVs will be a predominate point of reducing energy consumption and emissions for road transport, with an estimated reduction of approximately $40 \%-60 \%$. Furthermore, it has been estimated that through introducing AVs, traffic jams can be reduced and travel time can be saved, due to increased road capacity and improved traffic flow from better utilized transport infrastructure. ${ }^{6}$ As demonstrated by Steck et al. ${ }^{7}$ using mixed logit model that the autonomous driving (AD) effectively reduces the travel time for commuting trips, thereby, inducing more people to use AVs due to the benefits of shorter travel time. On the other hand, there is a large uncertainty in the impact of introducing AVs, with some studies indicating negative impacts on safety for non-AV road users, increased congestion and energy use, and issues of affordability and access. For example, a pedestrian was killed in the US by an autonomous Uber vehicle, which was under the self-driving mode in March 2018. ${ }^{8}$ In order to assess the impact of AVs on travel activities, Wadud et al. ${ }^{9}$ analyzed factors influencing people's

'Institute for Transport Studies, University of Leeds, Leeds, UK

${ }^{2}$ T-System International GMBH, Frankfurt, Germany

\section{Corresponding author:}

Jianbing Gao, LGOI, Building of Institute for Transport Studies (ITS), University of Leeds, Leeds LS2 9JT, UK

Email: redonggaojianbing@।63.com 
travel behaviors, such as reduced travel cost, saved energy consumption, and wider-scale user groups. Their results indicate an increase of travel demand in the overall vehicle travel, which may be detrimental to the efficiency of the transport system as a whole.

Many of the uncertainties and negative impacts that are predicted around AVs could be mitigated by the increased integration with the internet of things (IoT). IoT is a promising network system which communicates and transfers data or signal via a variety of smart devices (e.g. sensors, cameras, mobile phones) through cloud-based platform, without any interference from human. ${ }^{10-12}$ IoT technology, plays a crucial role in the development of AVs by improving the vehicle safety, security, and user acceptance. ${ }^{13}$ Current development focuses on the contribution of IoT to the functionality of AV guidance system. For example, to track the vehicles' locations in real time effectively, Global Positioning System (GPS) positioning devices, ${ }^{14}$ Global System for Mobile (GSM), and General Packet Radio Service (GPRS) communication systems ${ }^{15}$ with the control units were adopted and installed on the vehicles. A Smartphone app was also developed to monitor the movements of vehicle. Cyber-Physical System (CPS) sensors of autonomous vehicles were used to monitor a nearby traffic flow, which helped to optimize road traffic flow. ${ }^{16}$ By selecting the optimal parameters, such as velocity, brake distance, vehicle distance, and density, the routes of vehicles can be defined and enhanced. Further to positioning and environmental detection, IoT can be used to provide additional useful information to the vehicle or the user, such as upcoming hazards on a journey, the movements of vulnerable road users, or even social or leisure-related opportunities. ${ }^{17,18}$ As indicated by literature, ${ }^{19}$ a cloud-based smart parking system based on IoT was proposed to help users to reach an ideal parking spot more effectively, with the results of saving searching time.

The development of AV systems based on IoT $^{20}$ presents a huge potential for improving people's quality of life in an effective way, which can be achieved by different activities, such as automated valet parking (AVP), ${ }^{21}$ shared autonomous vehicles (SAVs). ${ }^{22}$ SAVs for example, includes a variety of different mobility service modes, such as station-based, free-floating, and peerto-peer car sharing. The test about free-floating car sharing service was conducted in London, ${ }^{23}$ finding that $37 \%$ of users clearly indicated that their attitude on private vehicles ownership has been affected by the adoption of free-floating car sharing. Thus, it presents a potential to decrease the number of private cars and lead to a more eco-friendly environment for the public. AVP system, ${ }^{24}$ as a part of travel planning, helps travelers to save travel time, increase energy efficiency, and improve the overall travel comfort. During the parking process, users' Smartphone app and camera, as human machine interface and parking area infrastructures, play a vital role for parking effectively.

AVP and SAVs, as new mobility service, inevitably have the potential to change people's living habits and compete with the current businesses related to personal conventional vehicles. All the businesses related to AVP and SAVs are in the process, and will bring about many affiliated businesses. Bellos et al. ${ }^{25}$ investigated the car sharing economy, and the results showed that the original equipment manufacturer (OEM) increased the fuel economy of the vehicles through car sharing. It was achieved by contemplating car sharing and designing its product line. Cohen and Kietzmann ${ }^{26}$ discussed the existing shared mobility business model to uncover the optimal relationship between service providers and local governments, with the results that the merit model in that work was the best alignment of agents and principals. Stocker and Shaheen ${ }^{27}$ reviewed the business models about SAVs, which was thought to be widespread in the future. As indicated in this work, the relation between the AV owners and SAV platforms would promote the development of a SAV service. Meanwhile, the profit and efficiency of the business are greatly dependent on the technology available, the location, vehicle types used, and ownership schemes. Also, the comparison of the cost structures between the private autonomous vehicles and the conventional (non-autonomous) vehicles are conducted. ${ }^{28}$ The results show that the AV technology helps to reduce the operating cost through lower insurance fees, maintenance, and fuel costs, although it raises the vehicle purchase price. It is consistent with Wadud's ${ }^{29}$ opinion that the vehicle operation will benefit from automation by performing the total cost of ownership analysis, which is because of the reduced driver costs through automation. The emergence of IoT poses a large impact on the current business model of manufacturing company. As indicated in the research, ${ }^{30}$ the main changes caused by IoT are that machine and plant companies are more concerned about workforce qualifications, while automotive suppliers are focused on improving cost efficiency. Applications of IoT can also be found in smart water management, ${ }^{31}$ aiming at a high efficiency in water distributions and consumptions, as well as system's maintenance and improvements.

Based on the reviews of the current business models about autonomous vehicles and IoT, few studies are conducted on the business models of AVP and SAVs assisted by IoT to date. However, the analysis of business model is quite important for all the stakeholders. This paper provides an overview of the business models of AVP and SAVs, with focus on car users and owners. The structure of this paper is organized in four parts: the first section examines the development and challenges of AVs, followed by the second section, which describes the roles of IoT technology promoting the development of AVP and SAVs. The third section proposes business models related to AVP and SAVs while examining the relationship between different stakeholders and analyzing the value proposition. The final section provides the cost structures of AVP and SAVs from the viewpoint of the car users and owners while also providing a sensitivity analysis of the main 


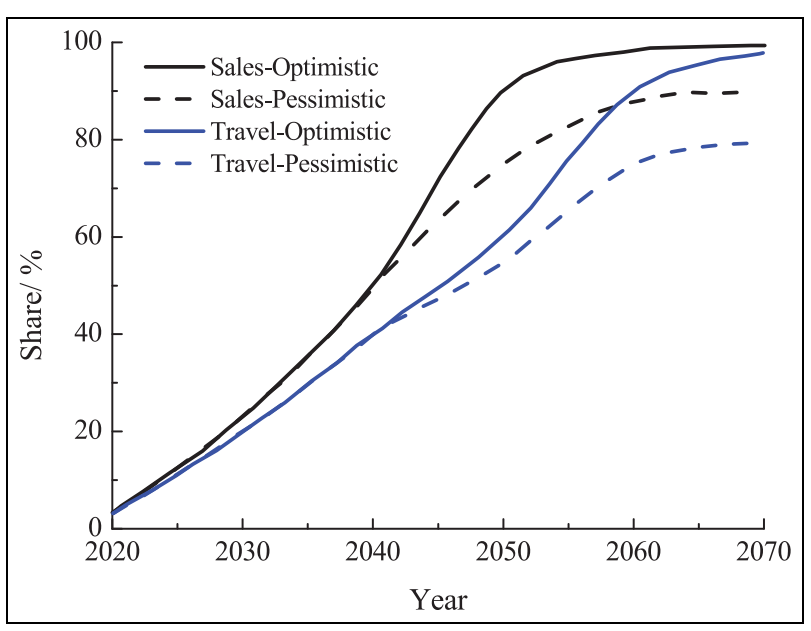

Figure I. The prediction of autonomous vehicle penetrations in the vehicle market. ${ }^{32}$

segment of the cost structure. The innovation of this paper is the analysis of business models of AVP and SAVs driven by IoT technologies. Also, it provides the elementary evidence for the potentials of developing AVP and SAVs by analyzing the cost structures of AVP and SAVs from the viewpoints of different stakeholders.

\section{Development and challenges of autonomous vehicles}

\section{Development of autonomous vehicles}

The predicted AVs penetrations in the vehicle market both in optimistic and pessimistic situations are shown in Figure 1, with the assumption that level 4-5 AVs are commercially available in $2020 .^{32}$ The level of autonomous vehicles in this figure refers to level $1-5$. It can be seen that in the first few decades, the market shares of AVs are low, which is limited by low vehicle performance (e.g. safety), high cost, legal issues, and low user acceptance. Due to the breakthrough of AVs technology, the market share increases significantly after 2040 , where the estimated market share difference between optimistic and pessimistic situations is enhanced. Examining the figure below, it can be observed that until 2060, the travel percentage by AVs is lower than the market share, which indicates that the mobility preference of people's travel is lower toward AVs. The development of AVs and the technology improvement thus, can greatly affect people's travel behavior, as indicated by Mares et al. ${ }^{33}$ that the travel distance miles can reach $85 \%$ higher if all vehicles are AVs. The changes of travel behavior can lead to the transformations of conventional business models to novel ones for all the stakeholders.

\section{Challenges of autonomous vehicles}

Autonomous vehicles can potentially overcome many current transport challenges, such as through improved

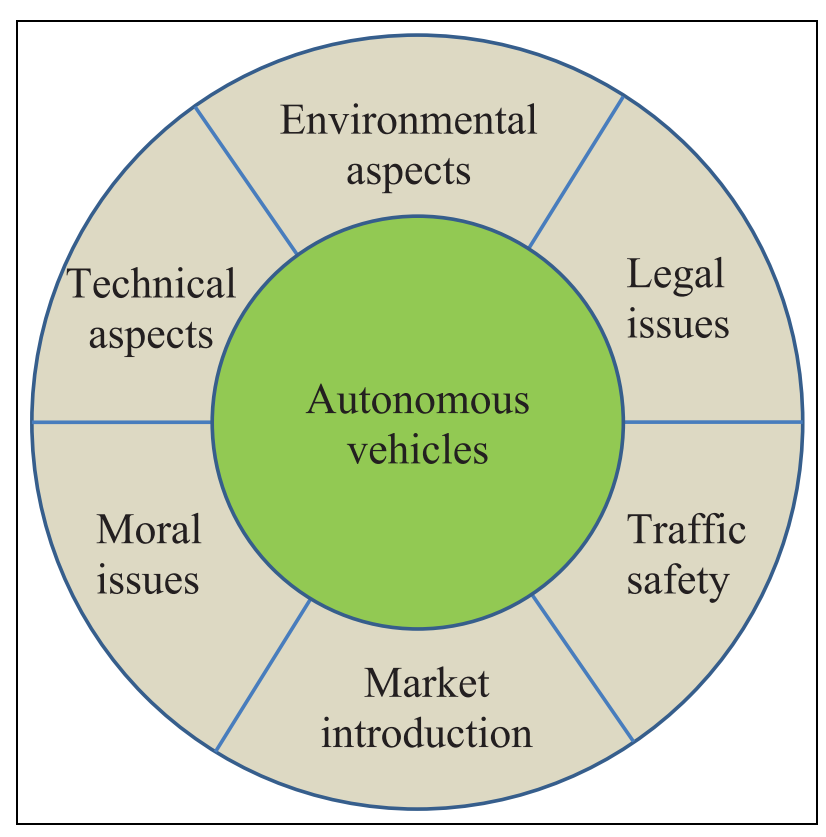

Figure 2. Challenges of autonomous vehicles.

road capacity, lower energy consumption, reduced pollution, and fewer accidents. ${ }^{32}$ However, all of these advantages are under the precondition of safety. Different from conventional vehicles, AVs are with limited involvement of drivers, accompanied by new challenges, as shown in Figure 2. The challenges include technical aspects, legal issues, traffic safety, moral issues, environmental aspects, and market introduction. For example, the AVs need to make decisions fast in a very short time, which also includes many moral dilemmas. ${ }^{34}$ The driverless aspect of the AVs makes the legal aspects significantly different from the conventional vehicles. The legal aspects of AVs involve not only technical aspects but also ethical aspects, such as data sharing in the process of $\mathrm{AVP}^{35}$ and SAVs. ${ }^{36}$ Another most important legal issue is the liability of autonomous vehicles, which has been reported in references. ${ }^{37,38}$ In order to implement the AVs, laws are needed from different levels of administrative, civil, insurance, infrastructure, and criminal aspects, whose challenges were discussed in detail by different studies. ${ }^{39-41}$ The improvement of the related law can accelerate the penetrations of autonomous vehicles.

\section{Autonomous vehicles promoted by internet of things technology}

Tesla Model X SUV and Tesla Model 3, the pioneer of AVs, involved two fatal incidents, which caused more worries about the safety of the AVs. These incidents have been considered to be a serious block for the widespread user application of AVs. Fortunately, IoT, as a novel technology, can be applied to AVs to improve the safety of autonomous driving. ${ }^{42}$ IoT can assist AVs to detect the hazards to avoid potential accidents. Surely, 


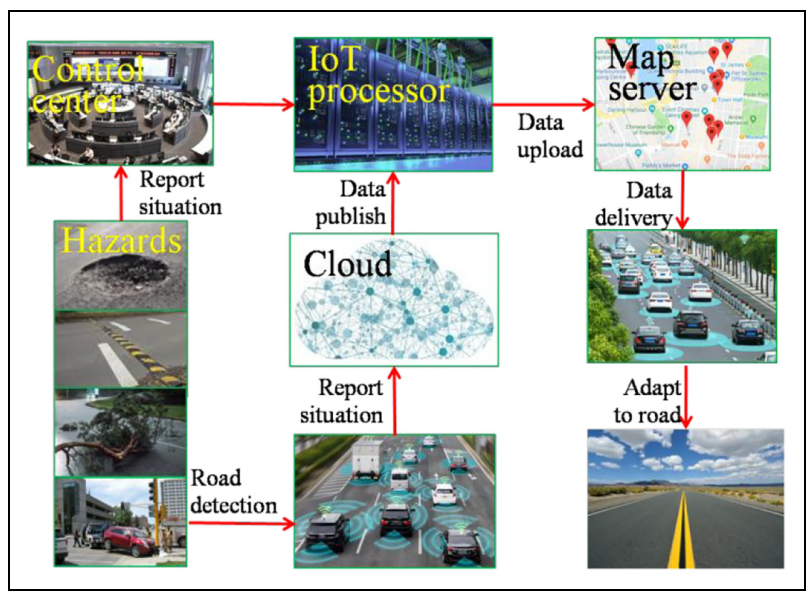

Figure 3. The approaches of internet of things assisting autonomous driving.

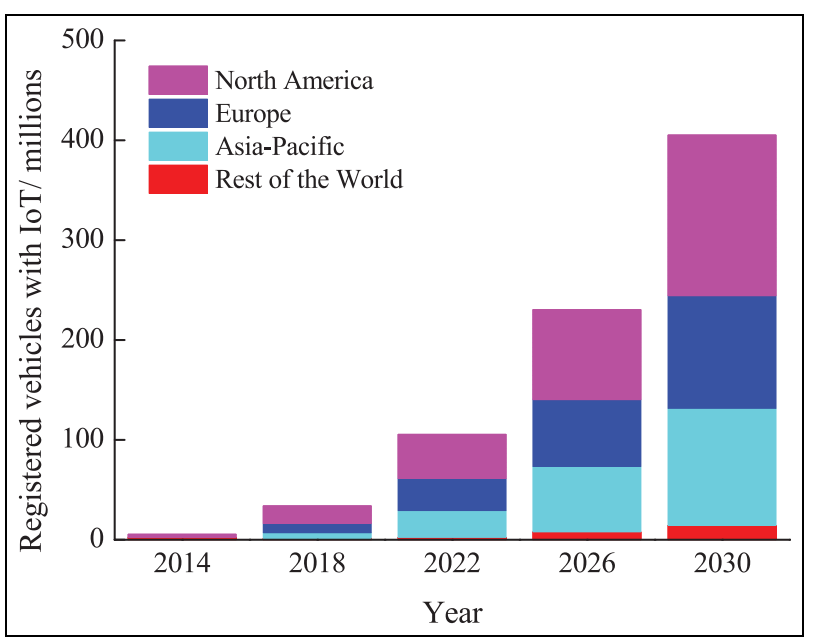

Figure 4. Autonomous vehicles development under the drive of internet of things. ${ }^{48}$.

IoT technology still has many technical challenges to the applications of AVs, e.g. reliability, robustness, sustainability, and resilience. ${ }^{43,44}$ Except for technical problems, the implementation of IoT technology allows private data sharing between customers and companies that may lead to financial or personal damages. ${ }^{45-47}$ Figure 3 shows one application of IoT technology assisting autonomous driving. IoT devices (e.g. cameras, sensors) both on vehicle and roads can detect hazards, such as potholes and obstructions, which may threaten the comfort or safety of the AV journey. The detected hazards will be reported to IoT processor (a cloud-based platform), which will upload the hazardous situations to a map server. Thus, other vehicles can get the information in advance from map server, and avoid the potential accidents. Note that some of this service can also be of benefit to non-autonomous drivers.

As indicated in some studies, ${ }^{48}$ IoT technology applied to AVs will increase greatly from year 2022, significantly driving the upgrade of AVs development from low level to high level (Figure 4). In the future, IoT technology will become more necessary to increase the security, users' acceptance, and experience. Under the development of IoT technology, AVs can have a higher market share. IoT technology not only promotes the development of AVs, but also stimulates the evolutions of the current related businesses. Additionally, it can change people's travel behavior, as shown in reference, ${ }^{33}$ that the miles traveled increase could reach $85 \%$, which implies the huge changes of travel behavior brought about by AVs. More registered vehicles with IoT devices conduces to the transitions from conventional vehicles to AVs.

The simple explanations of the way promoting AVP and SAVs are shown in Figure 5. AVP allows customers to get off anywhere, ${ }^{49,50}$ with the advantages of avoiding looking for a free parking spot with parking assistance of IoT. The operation of AVP needs the cooperation of AVs and parking spots that parking spots report their availabilities continually to the service provider, and AVs can get the free parking spots information. Meantime, the optimal route to parking spots can be planned to avoid the routes with hazards on the way. All these actions are done with the help of IoT,

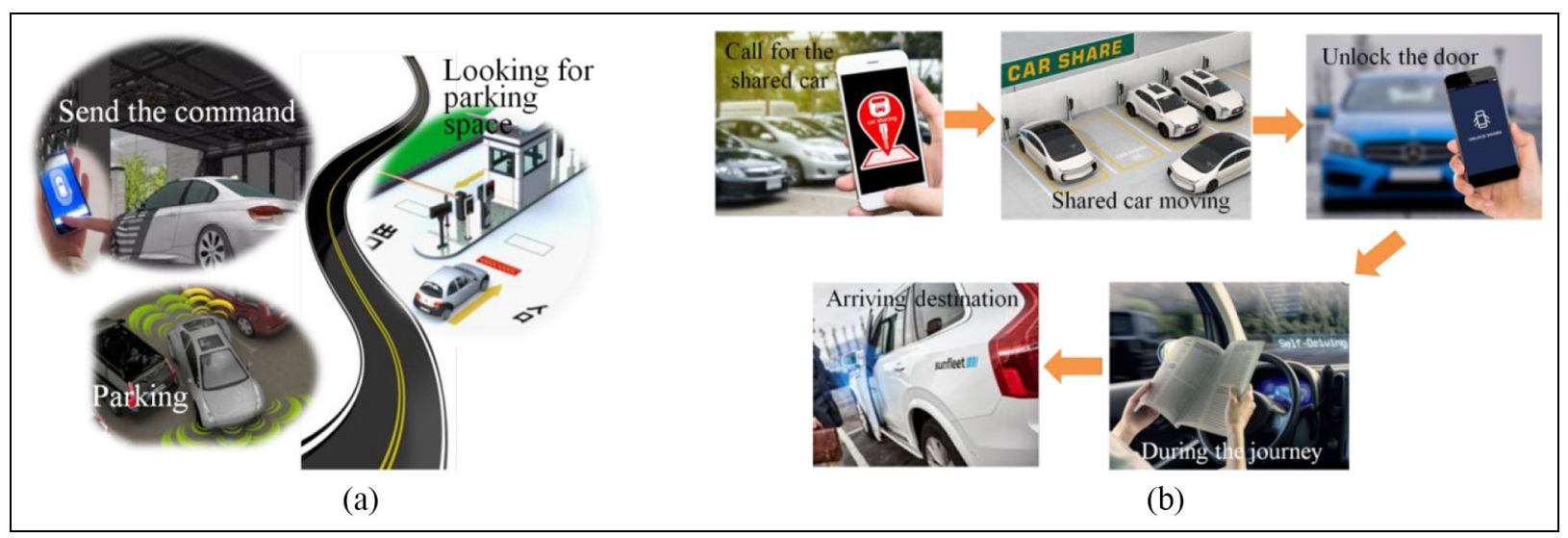

Figure 5. Operation models of automated valet parking and shared autonomous vehicles: (a) automated valet parking and (b) shared autonomous vehicles. 


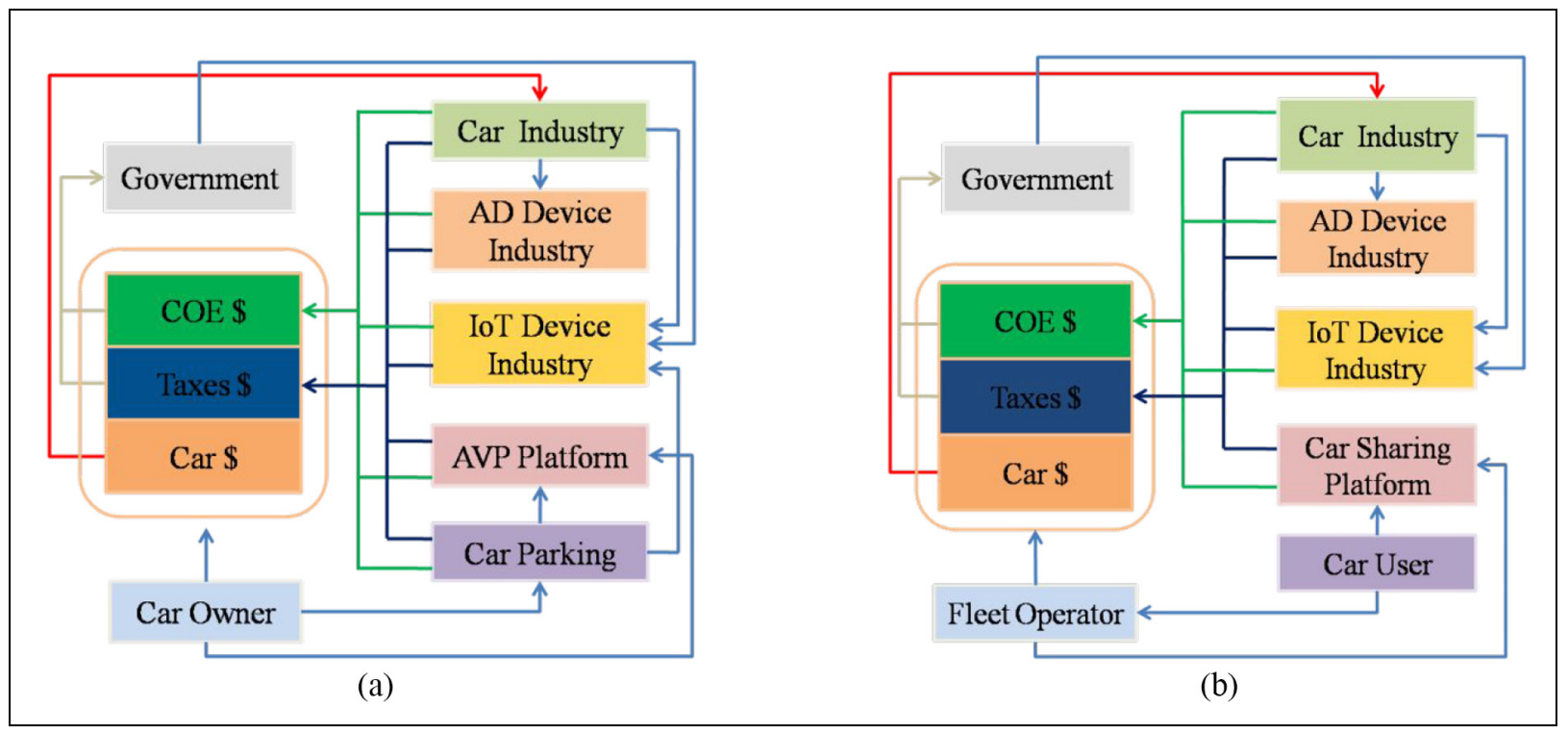

Figure 6. Simplified representation of new business models for automated valet parking and shared autonomous vehicles: (a) automated valet parking and (b) shared autonomous vehicles. Arrows indicate the direction of cost payment.

which makes the real time information available for all the related stakeholders. Shared autonomous vehicles usually includes three models: $:^{51,52}$ (1) station-based car sharing allows customers to collect and return the shared vehicle at the same place, the connections between the customers and autonomous vehicles are achieved by Radio Frequency Identification (RFID) access cards or apps installed on their mobiles. This type of car sharing is similar to car rental. (2) Freefloating car sharing provides customers flexibility of picking up and returning the shared cars in any authorized place, which addresses the one-way trip. As expected, the customers with SAVs need to pay further for the convenience compared with station-based car sharing. (3) Peer-to-peer car sharing allows the vehicle owners to make their personal vehicles shared with other users when available.

\section{Analysis of the automated valet parking and shared autonomous vehicle business models}

In this part, new business models of AVP and SAV are proposed, the revenue flows among the stakeholders are firstly analyzed; then, the business model canvas of AVP and SAV are used to explore the value proposition, infrastructure, customers, and finances among the stakeholders over the involvement of the IoT.

\section{New business models of automated valet parking and shared autonomous vehicles}

In July 2019, a milestone was reached by Bosch and Daimler on the way to AVP, whose license was approved from relevant authorities in BadenWürttemberg. AVP service was accessed by a Smartphone app, by which the automated parking order was sent. ${ }^{53}$ The application of IoT to AVP has contributed to the generation of new businesses and stakeholders. In this part, AVP and SAVs are taken to illustrate the new business models related to AVs (Figure 6). In the simplified traditional business model, only the car companies and car owners are related, while the AD package (software and hardware) companies, IoT device industries, service providers (AVP and SAVs), novel car parking companies, and fleet operators are also involved in the new business models. Especially for the service providers, which combine the car users and owners, the service quality from the providers greatly influences the experience of the two stakeholders, further affecting the business development. As for car sharing, if only the licenses of service provider and fleet operator are approved, the finance flow in the car sharing process can be generated. The adoption of IoT technology increases the reliability and security of AVs, which accelerates the acceptance of AVs. In the shared autonomous vehicles mode mentioned above, the car owners have incomes by sharing their cars. However, the car owners have the priority of using the vehicle in peer-to-peer car sharing, without influencing their own travel plan. Hence, the car sharing releases their financial burden to some extent but increases car maintenance. In the process of the AVP and SAVs, the government needs to devote much to the implementation from the regulations and infrastructures. The infrastructure is the foundation that ensures the functions of IoT technology to be achieved. 


\begin{tabular}{|c|c|c|c|c|c|}
\hline $\begin{array}{l}\text { Key Partners } \\
\text { - Local authorities (City) } \\
\text { - OEMs } \\
\text { - App developers / } \\
\text { suppliers } \\
\text { - Sensor developers/ } \\
\text { providers } \\
\text { - Drone developers/ } \\
\text { providers } \\
\text { - Navigation maps } \\
\text { - IoT platform providers } \\
\text { - Parking owners/ } \\
\text { operators } \\
\text { - Telecom operators }\end{array}$ & $\begin{array}{l}\text { Key Resources } \\
\text { - IoT road side } \\
\text { sensors and } \\
\text { equipment (e.g. } \\
\text { drones, cameras) } \\
\text { - Financials } \\
\text { - Key partners } \\
\text { - Legal regulatory }\end{array}$ & \multicolumn{2}{|c|}{$\begin{array}{l}\text { Value Propositions } \\
\text { - Private car owner: more } \\
\text { available parking space, } \\
\text { convenience/comfort, less } \\
\text { damages, optimized routes } \\
\text { to free parking space; } \\
\text { - Parking operator: less } \\
\text { damages, increased security, } \\
\text { saved space, increased } \\
\text { location attractiveness; } \\
\text { - Company: less damages, } \\
\text { increased efficiency; } \\
\text { - City: decreased number of } \\
\text { cars in the city, increased } \\
\text { efficiency/ space utilization, } \\
\text { decreased accidents; } \\
\text { generating new revenue; }\end{array}$} & $\begin{array}{l}\text { Customer Relationships } \\
\text { - Regulated by a contract but } \\
\text { strong partnership } \\
\text { - Membership }\end{array}$ & $\begin{array}{l}\text { Customer Segments } \\
\text { - Operation(s) } \\
\text { - ITS companies } \\
\text { - IoT platform providers } \\
\text { - Telecom infrastructure } \\
\text { suppliers }\end{array}$ \\
\hline \multicolumn{3}{|c|}{$\begin{array}{l}\text { Cost Structure } \\
\text { - IoT devices: drones, } \\
\begin{array}{ll}\text { cameras, ... ITS platform usage } \\
\text { - Data connectivity } & \text { - IoT platform usage } \\
\end{array}\end{array}$} & \multicolumn{3}{|c|}{$\begin{array}{l}\text { Revenue Streams } \\
\text { - Parking tickets } \\
\text { - Local/ national planning roadmap for less parked cars } \\
\text { - Long term operation and maintenance contract between the city } \\
\text { authority/ customer and the operator }\end{array}$} \\
\hline
\end{tabular}

Figure 7. Business model canvas for automated valet parking.

\section{Business model canvases of automated valet parking and shared autonomous vehicles}

The aim of the analysis of business models is to identify the aligned firms' activities by illustrating potential trade-off. $^{54}$ The business model canvas (BMC) as a strategic management template and a visual chart with nine different building blocks, is used to describe a firm's or product's value proposition, infrastructure, customers, and finances. ${ }^{55,56}$ In this part, the identified BMC for AVP and SAVs will be presented, which can be treated as a supplement further to explain the business model.

The value propositions of AVP solution can be considered from different viewpoints, as showed in Figure 7. The business model canvas is based on a workshop. Private car owners will benefit from time saving, more available parking space, more convenience and comfort, less damages, and optimized routes to the free parking space. For parking operator, AVP service assisted by IoT significantly decreases car damages and increases security in theory, meanwhile saving parking space and increasing the attractiveness of parking location. This service also contributes to the company by increasing efficiency and decreasing car damages, which is affirmed by Arnold et al. ${ }^{30}$ The changes of the current businesses are focused on the service quality and cost efficiency. The relations between IoT-assisted AVP and parking efficiency are shown in Figure 8. With the assistance of IoT, the available parking spots are easily found, which is one of the most important advantages promoting the AVP development, especially for those who have emergency appointments with limited parking space and far parking spots. Periodical maintenance is necessary to keep 


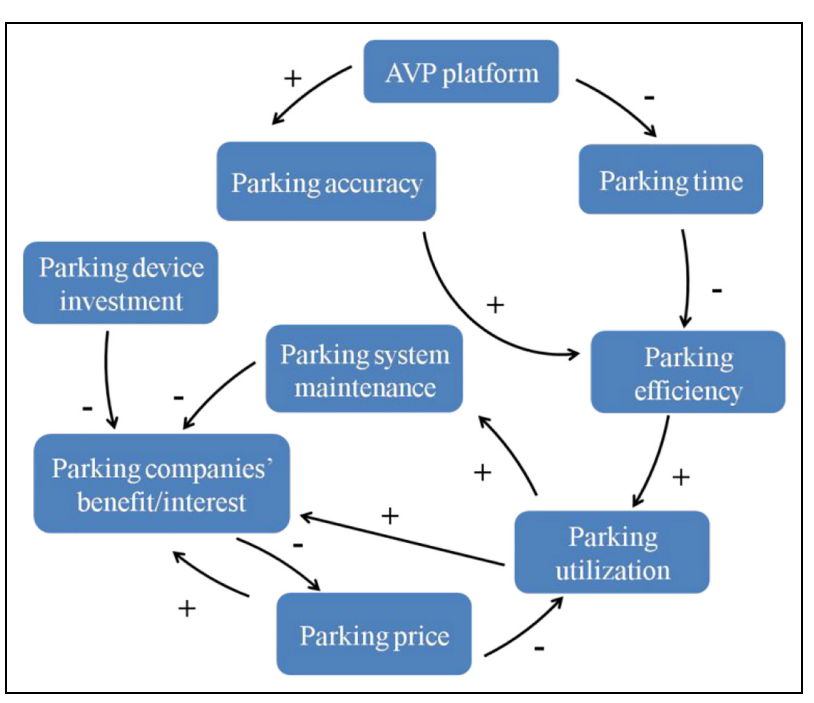

Figure 8. The relations of automated valet parking with parking efficiency and price.

high reliability of AVP. The service provider is also an important aspect for AVP system. It collects all the dynamic information of parking spaces, and shares the information with AVP users. The data processing efficiency of the service provider significantly determines the parking efficiency and accuracy, which influence the experience of AVP users and AVP development.
The service providers thus, have a huge challenge due to its importance in the AVP business.

The business model canvas of $\mathrm{SAVs}^{56}$ is shown in Figure 9. The value propositions of SAVs solution is contributed to the reduced congestions. The alleviated road congestions stimulate more people to use shared cars, as indicated in Figure 10. As the consequence, the finance flows between stakeholders change correspondingly. With this business model canvas, the actors and their interactions along the value train of SAVs can be well captured and structured, which facilitates a better understanding. Compared with autonomous driving business, new parts suppliers and activities are involved, which also leads to the transformation of the focuses in conventional business. The relationships in Figures 8 and 10 make the foundations of the system dynamic models that will be used to investigate the impacts on the revenue flows related to AVs. In the future system dynamic models, only the main factors mentioned in both figures will be used due to limited available data for other factors.

\section{Cost analysis of automated valet parking and shared autonomous vehicles for car users and car owners}

The use of AVs and IoT technology will put much pressure on the conventional car sharing business and

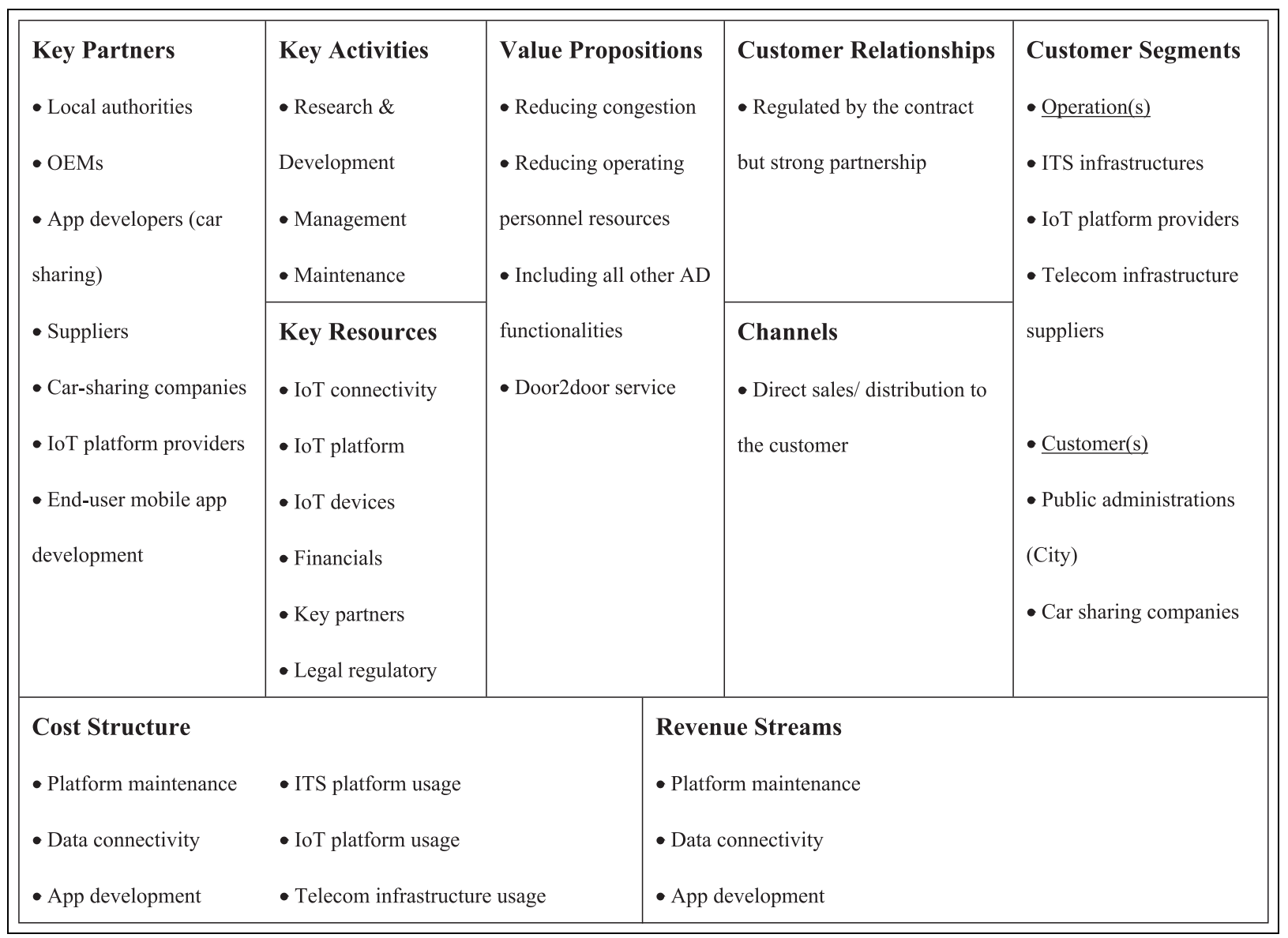

Figure 9. Business model canvas for shared autonomous vehicles. 


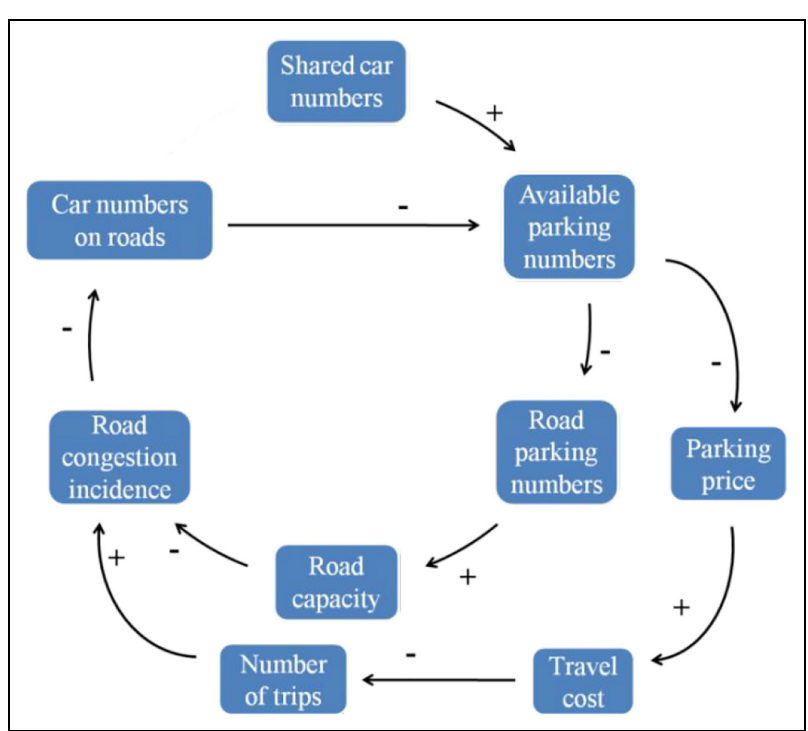

Figure 10. The relations of shared autonomous vehicles with road congestion and parking price.

promote their evolutions to shared autonomous vehicles, also, making the automated valet parking a reality. Parking activities and private car users will be mostly affected by people's travel habits such that large amounts of private car users will transfer to SAVs. This will contribute to the generation of new businesses, being completely different from the currently existing car sharing businesses. For example, the pick up stations need less receptions, but the high quality of online service and shared autonomous vehicle system should be guaranteed, which can be partly strengthened by the use of IoT technology. In this part, the conventional vehicle and the autonomous vehicle are used to analyze the cost structures of AVP and SAVs. It should be noted that the AVs are from the conventional vehicles (Mercedes-Benz C 180) by adding the AD package, and the detailed cost is based on London data. All the cost values are referred from the published materials and reasonable assumptions, as shown in the support information (Supplemental Tables S1-S5). The average vehicle age in European countries is $11-12$ years, ${ }^{57}$ here 12 years are taken as the vehicle age in this paper.

\section{Automated valet parking}

Due to the generation of new business related to AVP, the cost structures will be changed. Bösch et al. ${ }^{28}$ compared the cost structures of different types of autonomous vehicles with private conventional vehicle, the depreciation increased from $42 \%$ to $48 \%$, but other costs remained almost the same. A shortcoming of the work $^{28}$ is that the cost of AD package was neglected. However, the package cost was even higher than the vehicle itself, and the price dropped by $95 \%$ in the following 7 years. ${ }^{58}$ Figure 11 shows the cost structure of the conventional parking, which is taken as the baseline. In the first several years, the car depreciation and

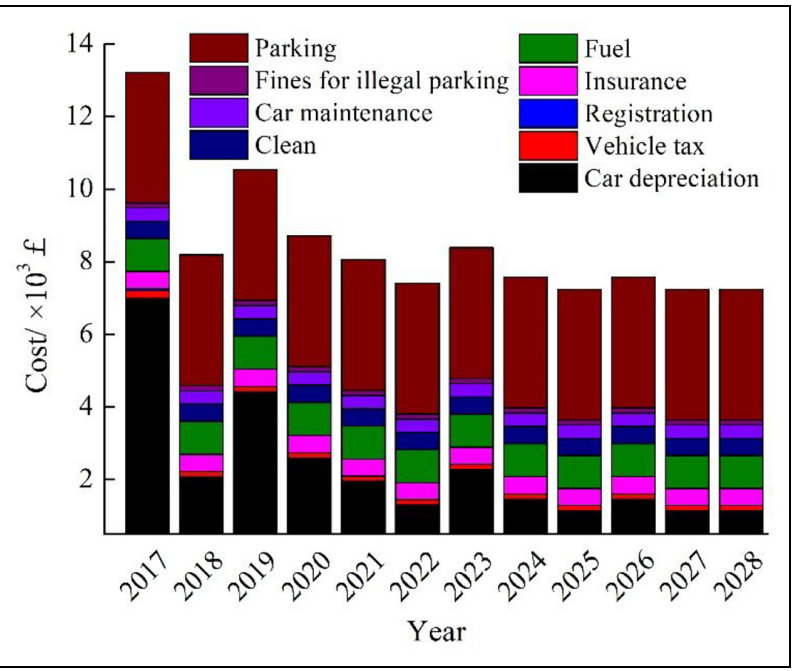

Figure II. Cost structure of conventional car parking users.

parking are the first two highest costs, and fuel cost is approximately $10 \%$, which is similar to that found in Bösch et al. ${ }^{28}$ The parking dominates the cost from the fourth year due to the high parking cost in London area. The total cost of the first year is the highest due to high depreciation rate, vehicle tax, and registration fee. A high depreciation rate means the value of a vehicle reduces significantly, and it was observed that the depreciation rate is less than $10 \%$ from the fourth year.

Although the cost of AD package decreases by $95 \%$ in the following years, and it is still high in the first several years, the cost structures of AVP will be quite different if AVs are purchased at different date, as shown in Figure 12 (starting years of 2017 and 2025). Compared with the conventional vehicle, the AD package dominated the cost structure distributions if the autonomous vehicle was purchased in 2017. The AD package cost was $\sim 60 \%$ at most in the first several years (Figure 12(a)). However, it decreases to less than $5 \%$ when purchased in 2025 (Figure 12(b)). The price drop of the AD package is caused by the development of the technology and enlargement of the production. Due to the use of autonomous driving, the car owners have to pay for the navigation and security fees. In AVP cost structure, the parking fee is assumed to be the same as conventional parking. As the vital technology, IoT can increase the parking efficiency and avoid the potential hazards on the way to the available parking spots. It effectively promotes the development of AVs and influences the businesses related to AVP. The IoT technology does not put much cost on customers since AVP does not need new devices to be installed, but rather the services. The services are based on the AVs and need to be authorized by nation, users and parking companies, and some paid software or apps needs to be installed in the vehicles or mobile phones. The service fees will be charged by the providers.

The adoption of AVP also effectively increases the parking efficiency, further decreasing the parking fee to some extent. The role of the parking fee increases 


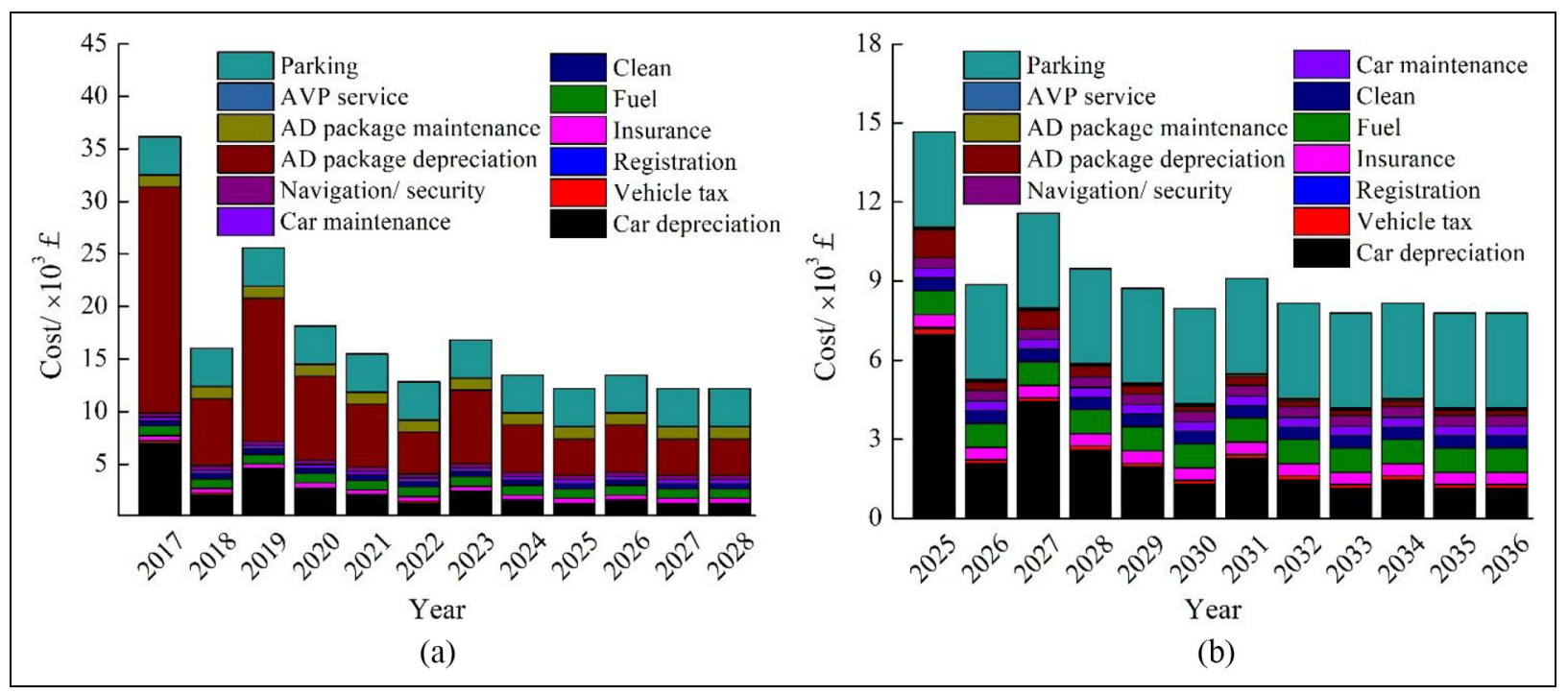

Figure 12. Cost structure of automated valet parking users: (a) starting year: 2017 and (b) starting year: 2025.

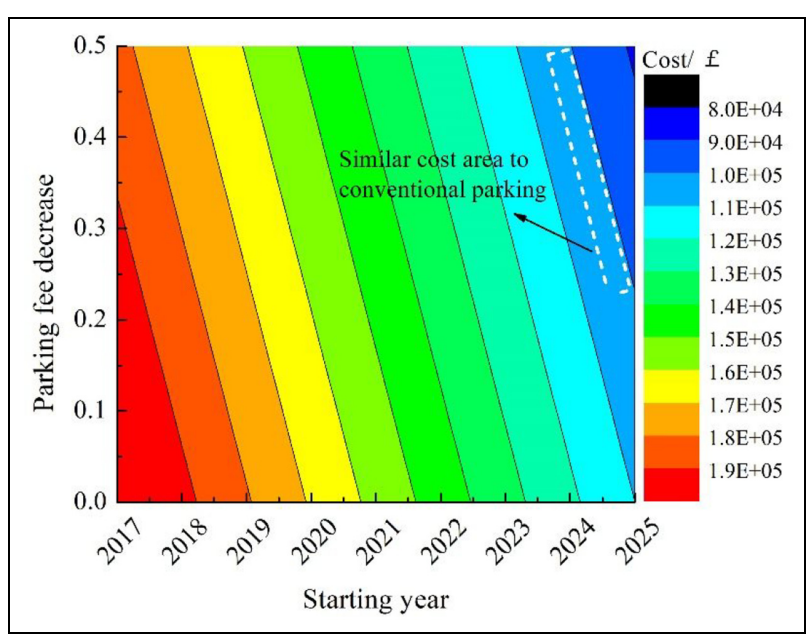

Figure 13. Twelve years' total cost of automated valet parking users.

gradually with the popularization of autonomous driving, as shown in Figure 12. Figure 13 shows the total cost (12 years, the average age of a vehicle) of AVP, with the variables of AVP starting year and the decrease of parking fee (parking discount) after the adoption of AVP. As can be seen, the total cost of AVP is much higher than the conventional parking before year 2024 due to the high cost of AD package if the parking fee decrease is less than $50 \%$. As indicated by the British parking association, British drivers take 4 days on average (48 days for 12 years) to look for parking spaces annually. ${ }^{59}$ It was also indicated by Shoup $^{60}$ that it takes $3.5-14$ min per car trip to find a parking space, and $8 \%-74 \%$ of traffic was cruising for parking. AVP is not only related to saving time, but the parking experience also affects people's emotion and life quality. It is related to the balance between the cost and the convenience benefit from AVP so that it deems the initial users are the rich who prefer high level of living standard. Conventional parking takes much time and it has the potential of making the parking spots more distant from the destinations, which may cause indirect loss to the customers, such as money, late for dating, missing for conferences. Moreover, cruising for parking consumes large amounts of energy (fuel and electricity). As indicated by Le Fauconnier and Gantelet, ${ }^{61}$ the average parking space searching time is 3.3, 11.8, 10, and $7.7 \mathrm{~min}$ for Grenoble, Paris, Commerce district, and Saint-Germain district, respectively. During AVP process, IoT helps to identify available parking space, which significantly reduces the time of looking for parking spots, with the results of cruising time reduction. ${ }^{50,62}$ Further, the road congestion and car energy consumption will decrease to some extent. In fact, except for the direct time benefit of parking, it also brings about much indirect merits, such as being punctual for meeting, avoiding illegal parking charges, and emergency cases. The indirect benefits are hard to be estimated due to the different situations, and it is related to the customers' willingness and budget to pay for the possibility of avoiding some indirect loss.

\section{Shared autonomous vehicles}

As mentioned above, the shared autonomous vehicles include three modes: station-based car sharing, freefloating car sharing, and peer-to-peer car sharing. The costs of these types of car sharing are completely different due to the services for both the car users and owners. In this part, the cost structures of these three types of car sharing are compared with conventional driving.

As indicated in Bösch et al., ${ }^{28}$ the payment for car owners in taking taxi accounted for $88 \%$ of the total cost, and this part of cost could be cancelled if autonomous taxis are used. The cost structures of private cars are complicated by large amounts of aspects, however, the cost structure is much simpler for SAVs, including 


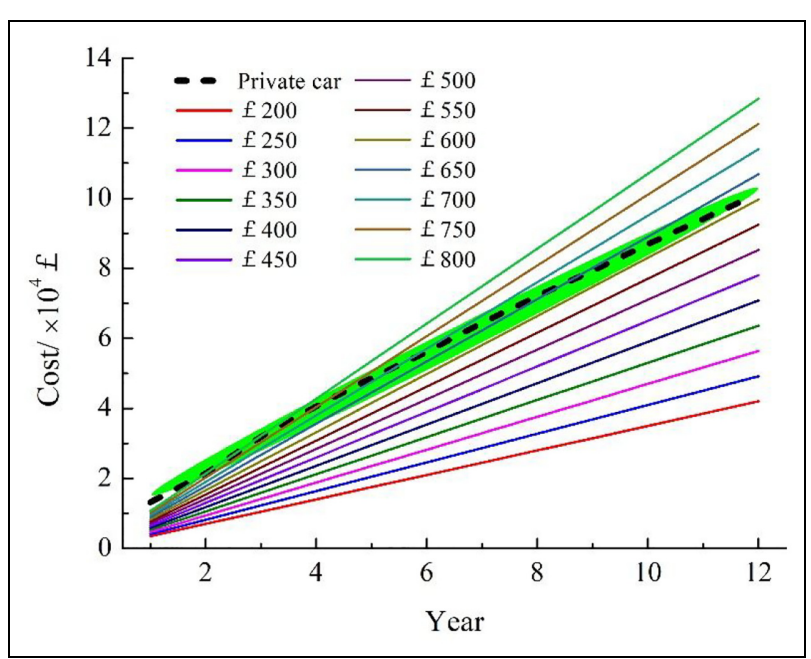

Figure 14. Twelve years' total cost of car sharing users.

rental fee, car sharing service fee, fuel cost, register fee, and illegal parking fee, which leads to the linear cost increase with the year. Compared with the fuel cost and rental fee, the car sharing service fee, register fee, and illegal parking fee are much lower. The total cost of car sharing as the function of year and monthly rental fee is shown in Figure 14, and it is compared with that of the private car. The cost of car sharing for users is at the same level with private car owner when the monthly rental fee is around $£ 650$. Regardless of the cost, car sharing could provide the opportunity of enjoying different types of cars. Also, the users will not be troubled by periodical car maintenance.

As discussed in the above section, car sharing modes mainly include station-based car sharing, free-floating car sharing, peer-to-peer car sharing. The cost segments are the same for the station-based car sharing and freefloating car sharing, except for monthly income. The monthly rental price of free-floating car sharing is higher than station-based car sharing, since the customers enjoy the conveniences caused by the flexibility of car picking up and dropping. The cost structure of station-based car sharing fleet operator is shown in Figure 15. The rental fee is the same as the value mentioned above in the cost structure of users. The assumption in the cost structure is that one vehicle can meet 1.5 people's travel requirements without any influence of users' plan. Similar to AVP cost structure, AD package dominates the tendency of the annual cost. The service cost in this paper only accounts for a small percentage, which is inconsistent with Bösch et al., ${ }^{28}$ who made a comprehensive cost analysis for various types of autonomous vehicles and hold the opinion that the service cost is the main cost factor of shared autonomous vehicles. Station-based car sharing is somewhat unrealistic for small towns being distant from the car stations. This is because the customers have to pick up and return the car to the distant station. Free-floating car sharing is suitable for huge city with large amounts of population and high demands of travel. However, it is more reasonable to compare the total cost in a vehicle's lifespan due to different depreciation rates. Figure 16 shows the total cost of station-based car sharing for fleet operator in 12 years, as the function of monthly rental income and the year that the autonomous vehicle is put into use. Profit zone means that the total cost of the station-based autonomous car sharing is less than the conventional car sharing. The rental fee is expected to be quite high if the fleet operator wants to get profit while the SAVs are put into use before 2020. As indicated by Münzel et al., ${ }^{63}$ the business of car sharing and private car will co-exist in a short time before the cost of the car owner decreases and the technology has a breakthrough in shared autonomous vehicles. The conclusion is consistent with the authors' opinion although the starting points of analyses are slightly different.

Different from the station-based and free-floating car sharing, car owners of peer-to-peer car sharing are both the users and car sharing providers. Car sharing

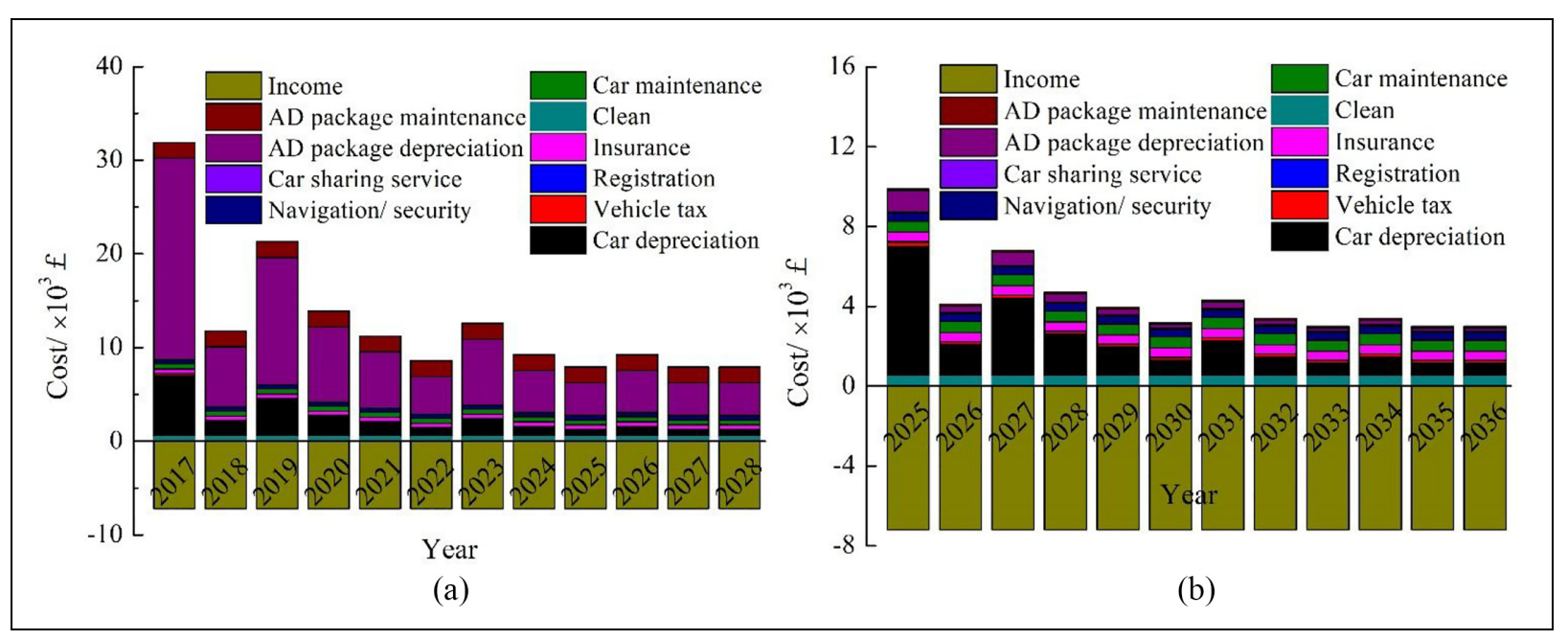

Figure 15. Cost structure of station-based car sharing fleet operator: (a) starting year: 2017 and (b) starting year: 2025. 


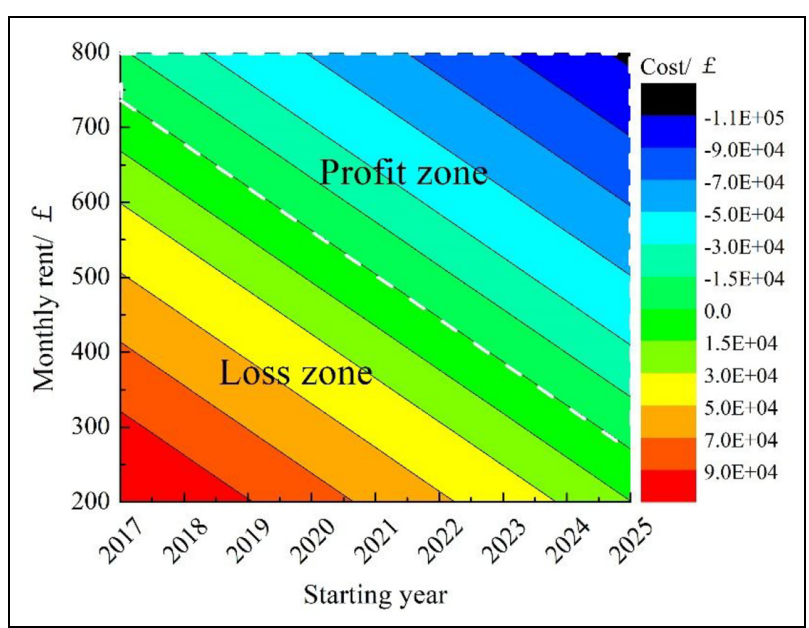

Figure 16. Twelve years' total cost of station-based car sharing fleet operator.

can decrease their financial burdens under the conditions of their travel being free from the effect of car sharing actions. Figure 17 shows the cost structure of peer-to-peer car sharing for car owners, with the assumption that one autonomous vehicle can meet extra 0.5 people's requirement, and the maintenance cost increases in the same percentage accordingly. The cost structure of car owners is similar to AVP, but results in higher maintenance cost (both car and AD package) due to higher mileages by the car sharing users. The car sharing will not decrease much financial pressure for car owners if the AV was purchased in 2017 , the decrease is less than $20 \%$. The AD package depreciation dominates the cost in the first several years, and the percentage of parking fee is significant. However, the cost of peer-to-peer car sharing users starting from 2025 decreases by $\sim 60 \%$ in the first year compared with 2017 start users. The rental income is much similar to parking fee, which accounts for a huge share. Figure 18 shows the total cost for peer-to-peer car sharing owners. The autonomous car will add more financial burden on the car owners compared with conventional car before the breakthrough of autonomous driving, which results in the significant decrease of selfdriving package price. Plenter et al. ${ }^{64}$ also analyzed the business model of peer-to-peer car sharing, where the peer-provider's own business was addressed. In order to ensure the car owners' and users' benefits, the SAVs can be put into the market only after year 2022, in the authors' opinion.

In the authors' opinion, another car sharing mode should be developed, such as the home-to-destination car sharing such that users can order the car which will come to the place which is the most convenient for users, and return to the nearest station by itself after use, without the cars being picked up and returned by the users. This mode of car sharing is easy to realize due to the characteristics of autonomous driving. It will be beneficial for people living in the town, and not far from the car sharing stations. It is evitable that the car users should pay for the fees between stations and home. Additionally, the combinations of AVP and SAVs will bring more convenience for the users and promote the evolutions of current car sharing businesses.

In order to meet the requirement of autonomous driving, and enhance user acceptance, the producers of AD package (software and hardware) should improve the quality and decrease the package cost by developing the technology. Being the direct link between car users and car owners, the service provider is the foundation of AVP and SAVs businesses. It significantly influences the users' experience of autonomous driving and further affects its popularization. With the development of autonomous driving, the infrastructures and related regulations should be implemented to accelerate the development of autonomous vehicles. These new kinds of things will bring about large amounts of new businesses and job opportunities.

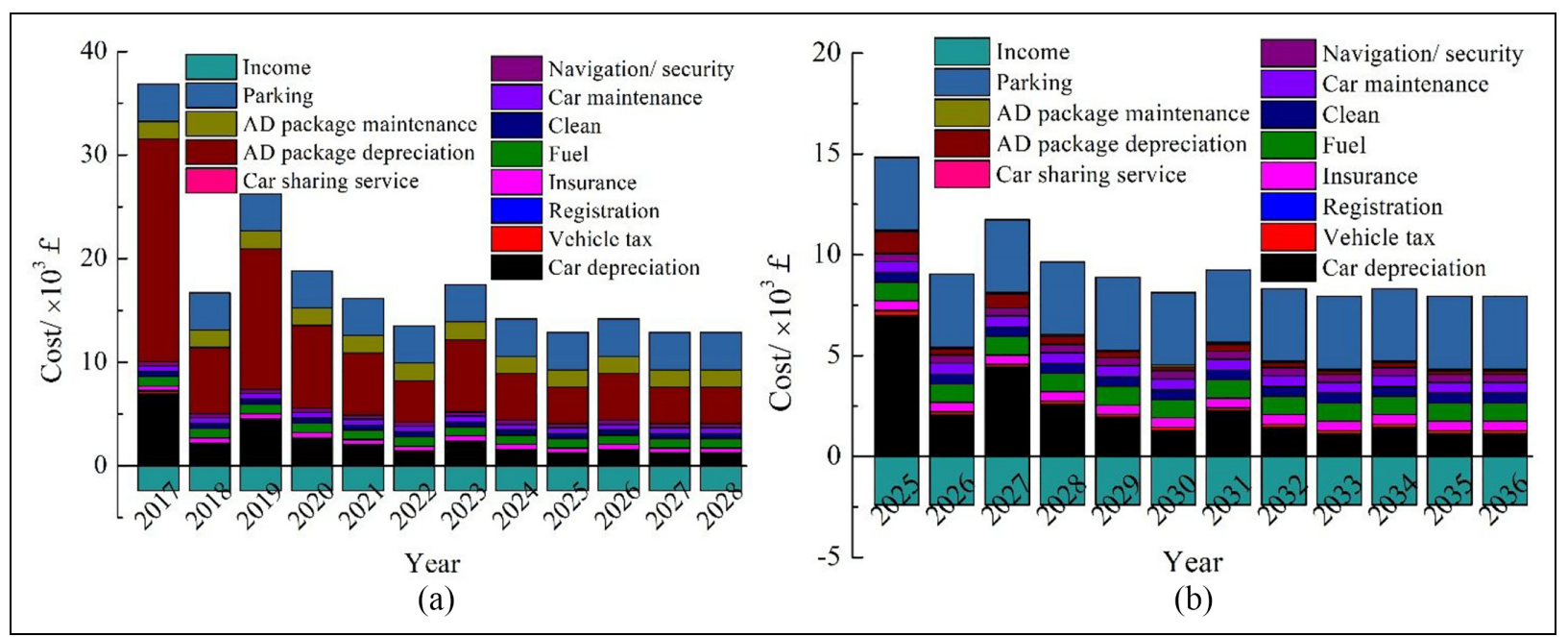

Figure 17. Cost structure of peer-to-peer car sharing owners: (a) starting year: 2017 and (b) starting year: 2025. 


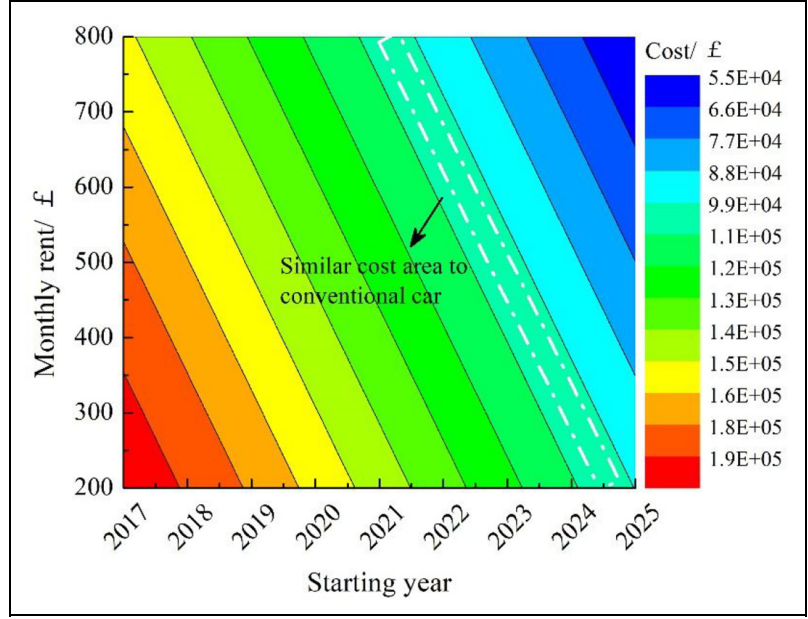

Figure 18. Twelve years' total cost of peer-to peer car sharing owners.

\section{Conclusion}

Autonomous driving, as a new travel activity, will significantly change people's lifestyle. The development of autonomous vehicles will be accelerated by the use of IoT, which will make autonomous driving more safe and acceptable. Meantime, new businesses will be generated and cause the transformation of the current business model. This paper introduces business models related to two cases of autonomous driving, AVP and SAVs. The cost structures under the two cases are analyzed from the points of different stakeholders. The conclusion is as following:

(1) In the business models, AD package and service providers of AVP and SAVs are new stakeholders, which link the car owners, car industry, also car parking for AVP and fleet operator for SAVs. The existence of AVP and SAVs will bring about more jobs opportunities, and increase the revenue of the nations. IoT plays an important role in promoting autonomous driving so that it provides much more convenience for car users. The adoption of IoT technology also promotes the evolution of the current business models related to AVs.

(2) Parking fee and car depreciation dominate the total cost of conventional parking, however, the parking fee, car depreciation, and AD package are the main cost for AVP. The AD package fee is approximately $60 \%$ of the total cost, however, the value decreases to $5 \%$ at most. The total cost of AVP for users are more than the conventional parking before 2024 . For car parking companies, the adoption of AVP with IoT assistance can effectively increase parking efficiency and parking utilization.

(3) When the monthly car rental fee is less than $£ 650$, car sharing decreases the total cost of travel, also making them free of the trouble of periodical maintenance for users. The cost structures are similar for the station-based and free-floating car sharing businesses, except for the monthly income. The benefits greatly depend on the AD package price. The peer-to-peer car sharing owners effectively decrease their financial burden if the business begins from year 2025, however, the benefit is less than $20 \%$ starting from 2017.

\section{Definitions/Abbreviations}

$\begin{array}{ll}\text { AD: } & \text { autonomous driving } \\ \text { AV: } & \text { autonomous vehicle } \\ \text { AVP: } & \text { automated valet parking } \\ \text { BMC: } & \text { business model canvas } \\ \text { COE: } & \text { certificate of entitlement } \\ \text { CPS: } & \text { cyber-physical system } \\ \text { GPRS: } & \text { general packet radio service } \\ \text { GPS: } & \text { global positioning system } \\ \text { GSM: } & \text { global system for mobile } \\ \text { IoT: } & \text { internet of things } \\ \text { ITS: } & \text { intelligent transport system } \\ \text { OEM: } & \text { original equipment manufacturer } \\ \text { RFID: } & \text { radio frequency identification } \\ \text { SAV: } & \text { shared autonomous vehicle }\end{array}$

\section{Declaration of conflicting interests}

The author(s) declared no potential conflicts of interest with respect to the research, authorship, and/or publication of this article.

\section{Funding}

The author(s) disclosed receipt of the following financial support for the research, authorship, and/or publication of this article: The research described in this paper was supported in part by the EU-funded project AUTOPILOT (grant agreement No. 731993).

\section{ORCID iD}

Jianbing Gao (D) https://orcid.org/0000-0002-9724-5789

\section{Supplemental material}

Supplemental material for this article is available online.

\section{References}

1. Jo K, Kim J, Kim D, et al. Development of autonomous car-Part II: a case study on the implementation of an autonomous driving system based on distributed architecture. IEEE Trans Ind Electron 2015; 62: 5119-5132.

2. Bimbraw K. Autonomous cars: past, present and future a review of the developments in the last century, the present scenario and the expected future of autonomous vehicle technology. In: 2015 12th international conference on informatics in control, automation and robotics (ICINCO), Colmar, France, 21-23 July 2015, pp.191198. New York: IEEE. 
3. Greenblatt JB and Shaheen S. Automated vehicles, ondemand mobility, and environmental impacts. Curr Sustain Renew Energy Report 2015; 2(3): 74-81.

4. Bagloee SA, Tavana M, Asadi M, et al. Autonomous vehicles: challenges, opportunities, and future implications for transportation policies. J Mod Transp 2016; 24: 284-303.

5. Igliński $\mathrm{H}$ and Babiak M. Analysis of the potential of autonomous vehicles in reducing the emissions of greenhouse gases in road transport. Procedia Eng 2017; 192: 353-358.

6. Friedrich B. The effect of autonomous vehicles on traffic. In: Maurer M, Gerdes J, Lenz B, et al. (eds) Autonomous driving. Berlin/Heidelberg: Springer, 2016, pp.317-334.

7. Steck F, Kolarova V, Bahamonde-Birke F, et al. How autonomous driving may affect the value of travel time savings for commuting. Transp Res Rec 2018; 2672: 1120.

8. Griggs $\mathrm{T}$ and Wakabayashi D. How a self-driving Uber killed a pedestrian in Arizona. The New York Times, 19 March 2018, p.3.

9. Wadud Z, MacKenzie D and Leiby P. Help or hindrance? The travel, energy and carbon impacts of highly automated vehicles. Transp Res Part A Policy Pract 2016; 86: 1-18.

10. Akpakwu GA, Silva BJ, Hancke GP, et al. A survey on $5 \mathrm{G}$ networks for the Internet of Things: communication technologies and challenges. IEEE Access 2017; 6: 3619 3647.

11. Singh $\mathrm{S}$ and Singh N. Internet of Things (IoT): security challenges, business opportunities \& reference architecture for E-commerce. In: 2015 international conference on green computing and internet of things (ICGCIoT), Noida, India, 8-10 October 2015, pp.1577-1581. New York: IEEE.

12. Madakam $\mathrm{S}$, Ramaswamy $\mathrm{R}$ and Tripathi $\mathrm{S}$. Internet of Things (IoT): a literature review. J Comput Commun 2015; 3: 164.

13. Reschka A. Safety concept for autonomous vehicles. In: Maurer M, Gerdes J, Lenz B, et al. (eds) Autonomous driving. Berlin/Heidelberg: Springer, 2016, pp.473-496.

14. Cui Y and Ge SS. Autonomous vehicle positioning with GPS in urban canyon environments. IEEE Trans Rob Autom 2003; 19: 15-25.

15. Lee S, Tewolde G and Kwon J. Design and implementation of vehicle tracking system using GPS/GSM/GPRS technology and smartphone application. In: 2014 IEEE world forum on internet of things (WF-IoT), Seoul, South Korea, 6-8 March 2014, pp.353-358. New York: IEEE.

16. Chen B, Yang Z, Huang S, et al. Cyber-physical system enabled nearby traffic flow modelling for autonomous vehicles. In: 2017 IEEE 36th international performance computing and communications conference (IPCCC), San Diego, CA, 10-12 December 2017, pp.1-6. New York: IEEE.

17. Niles JE. Autonomous vehicle environment detection system. Google Patents, US 14/521,866, 2016.

18. Ljubuncic I, Sack R, Rider T, et al. Autonomous vehicle safety systems and methods. Google Patents, US 14/ 752,572, 2016.

19. Pham TN, Tsai M-F, Nguyen DB, et al. A cloud-based smart-parking system based on Internet-of-Things technologies. IEEE Access 2015; 3: 1581-1591.
20. Lin $Y$ and Shen H. Vshare: a wireless social network aided vehicle sharing system using hierarchical cloud architecture. In: 2016 IEEE first international conference on internet-of-things design and implementation (IoTDI), Berlin, Germany, 4-8 April 2016, pp.37-48. New York: IEEE.

21. Möller DP and Haas RE. Connected parking and automated valet parking. In: Möller DP and Haas RE (eds) Guide to automotive connectivity and cybersecurity. Cham, Switzerland: Springer, 2019, pp.485-511.

22. Menon N, Barbour N, Zhang Y, et al. Shared autonomous vehicles and their potential impacts on household vehicle ownership: an exploratory empirical assessment. Int J Sustain Transp 2019; 13: 111-122.

23. Le Vine $\mathrm{S}$ and Polak J. The impact of free-floating carsharing on car ownership: early-stage findings from London. Transp Policy 2017; 75: 119-127.

24. Löper C, Brunken C, Thomaidis G, et al. Automated valet parking as part of an integrated travel assistance. In: 16th international IEEE conference on intelligent transportation systems (ITSC 2013), The Hague, Netherlands, 6-9 October 2013, pp.2341-2348. New York: IEEE.

25. Bellos I, Ferguson $M$ and Toktay LB. The car sharing economy: interaction of business model choice and product line design. Manuf Serv Oper Manag 2017; 19: 185-201.

26. Cohen B and Kietzmann J. Ride on! Mobility business models for the sharing economy. Organ Environ 2014; 27: 279-296.

27. Stocker A and Shaheen S. Shared automated vehicles: review of business models. International Transport Forum Discussion Paper, 2017.

28. Bösch PM, Becker F, Becker H, et al. Cost-based analysis of autonomous mobility services. Transp Policy 2018; 64: 76-91.

29. Wadud Z. Fully automated vehicles: a cost of ownership analysis to inform early adoption. Transp Res Part A Policy Pract 2017; 101: 163-176.

30. Arnold C, Kiel D and Voigt K-I. How the industrial internet of things changes business models in different manufacturing industries. Int J Innov Manag 2016; 20: 1640015.

31. Robles T, Alcarria R, Martín D, et al. An internet of things-based model for smart water management. In: 2014 28th international conference on advanced information networking and applications workshops, Victoria, BC, Canada, 13-16 May 2014, pp.821-826. New York: IEEE.

32. Litman T. Autonomous vehicle implementation predictions: implications for transport planning. Victoria, British Columbia: Victoria Transport Policy Institute, 2015.

33. Mares R, Stix C and Dewey S. How autonomous vehicles will drive our budgets. Report, Conservation Law Foundation, June 2018, pp.1-41.

34. Barabás I, Todoruţ A, Cordoş N, et al. Current challenges in autonomous driving. In: IOP conference series: materials science and engineering, Pitesti, Romania, 8-10 November 2017, p.012096. IOP Publishing.

35. Rottmann S, Timpner J and Wolf L. Demo: automated valet parking and charging. In: 2014 IEEE vehicular networking conference (VNC), Paderborn, Germany, 3-5 December 2014, pp.203-204. New York: IEEE.

36. Dominic D, Chhawri S, Eustice RM, et al. Risk assessment for cooperative automated driving. In: Proceedings of the 2nd ACM workshop on cyber-physical systems 
security and privacy, October 2016, pp.47-58. New York: ACM.

37. Anderson JM, Kalra N and Wachs M. Liability and regulation of autonomous vehicle technologies. Berkeley, CA: RAND Corporation, 2009.

38. Gurney JK. Sue my car not me: products liability and accidents involving autonomous vehicles. J Law Technol Policy 2013: 247-277.

39. Ilková V and Ilka A. Legal aspects of autonomous vehicles - an overview. In: 2017 21st international conference on process control ( $P C$ ), Strbske Pleso, Slovakia, 6 9 June 2017, pp.428-433. New York: IEEE.

40. Milakis D, Van Arem B and Van Wee B. Policy and society related implications of automated driving: a review of literature and directions for future research. $J$ Intell Transp Syst 2017; 21: 324-348.

41. GAD Comment. Government report: https://www.gov.uk/ government/publications/gad-comment-climate-change

42. Joy J, Rabsatt V and Gerla M. Internet of vehicles: enabling safe, secure, and private vehicular crowdsourcing. Internet Technol Lett 2018; 1: e16.

43. Gazis V, Goertz M, Huber M, et al. Short paper: IoT: challenges, projects, architectures. In: 2015 18th international conference on intelligence in next generation networks, Paris, France, 17-19 February 2015, pp.145-147. New York: IEEE.

44. Kaur J and Kaur K. Internet of Things: a review on technologies, architecture, challenges, applications, future trends. Int J Comput Netw Inf Secur 2017; 9: 57.

45. Weinberg BD, Milne GR, Andonova YG, et al. Internet of Things: convenience vs. privacy and secrecy. Bus Horiz 2015; 58: 615-624.

46. Caron X, Bosua R, Maynard SB, et al. The Internet of Things (IoT) and its impact on individual privacy: an Australian perspective. Comput Law Secur Rev 2016; 32: 4-15.

47. Maras M-H. Internet of Things: security and privacy implications. Int Data Priv Law 2015; 5: 99.

48. Krasniqi X and Hajrizi E. Use of IoT technology to drive the automotive industry from connected to full autonomous vehicles. IFAC-PapersOnLine 2016; 49: 269-274.

49. Chirca M, Chapuis R and Lenain R. Autonomous valet parking system architecture. In: 2015 IEEE 18th international conference on intelligent transportation systems, Las Palmas, Spain, 15-18 September 2015, pp.2619-2624. New York: IEEE.

50. Huang C, Lu R, Lin X, et al. Secure automated valet parking: a privacy-preserving reservation scheme for autonomous vehicles. IEEE Trans Veh Technol 2018; 67: 11169-11180.

51. Miao H, Jia H, Li J, et al. Autonomous connected electric vehicle (ACEV)-based car-sharing system modeling and optimal planning: a unified two-stage multi-objective optimization methodology. Energy 2019; 169: 797-818.

52. Cohen A and Shaheen S. Planning for shared mobility. Berkeley: University of California, 2018.

53. Bosch, and Daimler obtain approval for driverless parking without human supervision; SAE Level 4. Green Car Congress, 2019, https://www.greencarcongress.com/2019/ 07/20190724-boschdaimler.html

54. Perboli G, Ferrero F, Musso S, et al. Business models and tariff simulation in car-sharing services. Transp Res Part A Policy Pract 2018; 115: 32-48.

55. Toglaw S, Aloqaily $M$ and Alkheir AA. Connected, autonomous and electric vehicles: the optimum value for a successful business model. In: 2018 fifth international conference on internet of things: systems, management and security, Valencia, Spain, 15-18 October 2018, pp.303308. New York: IEEE.

56. Barnard Y, Federley M, Nikolaou S, et al. D4.4 preliminary business impact assessment. AUTOmated driving Progressed by Internet Of Things 2018, https://europeaniot-pilots.eu/project/autopilot/

57. Average age of the EU motor vehicle fleet by vehicle type. https://www.eea.europa.eu/data-and-maps/indicators/aver age-age-of-the-vehicle-fleet/average-age-of-the-vehicle-8 (2019).

58. Lienert P. Cost of driverless vehicles to drop dramatically: Delphi CEO. Insur J 2017, https://www.insurancejour nal.com/news/national/2017/12/05/473134.htm

59. Sawer P. Motorists spend four days a year looking for a parking space. https://www.telegraph.co.uk/news/2017/ 02/01/motorists-spend-four-days-year-looking-parkingspace/ (2017).

60. Shoup DC. Cruising for parking. Transp Policy 2006; 13: 479-486.

61. Le Fauconnier A and Gantelet E. The time looking for a parking space: strategies, associated nuisances and stakes of parking management in France. In: European transport conference (ETC), Association for European transport (AET), West Kensington, London, 2006.

62. SR MB. Automatic smart parking system using Internet of Things (IOT). Int J Sci Res Publ 2015; 5(12): 629-632.

63. Münzel K, Boon W, Frenken K, et al. Carsharing business models in Germany: characteristics, success and future prospects. Inf Syst e-Bus Manag 2018; 16: 271-291.

64. Plenter F, Fielt E, Hoffen M, et al. Repainting the business model canvas for peer-to-peer sharing and collaborative consumption. In: Proceedings of the 25th European conference on information systems (ECIS), Guimarães, Portugal, 5-10 June 2017, pp.2234-2249. AIS Electronic Library (AISeL). 